\title{
The Use of Flow Analysis in Foreign Exchange:
}

\section{Exploratory Evidence}

\author{
Thomas Gehrig, Universität Freiburg und CEPR London \\ Lukas Menkhoff, Universität Hannover ${ }^{a}$
}

Discussion paper No. 276

March, 2003

ISSN 0949-9962

\begin{abstract}
:
This paper provides questionnaire evidence on the role of flow analysis for professional traders and fund managers. This evidence suggests that besides fundamental information and technical analysis, the analysis of flows provides an independent third type of information for professionals. The view that flows can be used to learn about fundamentals is not consistent with the data. Instead, evidence indicates that flows more likely provide insight into semi-fundamental private information. [forthcoming JIMF 2004]

JEL-Classification: F31

Keywords: foreign exchange markets, flow trading, market microstructure

${ }^{a}$ Corresponding author.

Department of Economics, University of Hannover, Königsworther Platz 1, 30167 Hannover, Germany; email address: menkhoff@gif.uni-hannover.de
\end{abstract}




\section{The Use of Flow Analysis in Foreign Exchange:}

\section{Exploratory Evidence}

\section{Introduction}

"A source of informational advantage to the traders is their access to, and trained interpretation of, the information contained in the order flow" (Goodhart, 1988, p.456). Although this has been common market wisdom for a long time, there have been no studies that systematically examine the use of flow analysis by foreign exchange professionals. This paper provides evidence that next to fundamental and technical analysis the analysis of flows is an independent third type of information. We thus add to the recent literature by presenting empirical evidence that the analysis of flows does affect the behavior of a significant group of professional FX market participants according to their own perspective.

Thus, our contribution complements other work about the informational role of flows. For example, Lyons $(1995,1998)$ presents case study evidence on the importance of flows, Osler (1998) relies on flows to characterize exchange rate changes, Ito, Lyons and Melvin (1998), Covrig and Melvin (2001) provide statistical evidence for information inherent in flows and Cai, Cheung, Lee and Melvin (2001), Evans (2001) and Evans and Lyons (2002) improve exchange rate explanation by incorporating order flows.

According to Lyons (2001, p.4), "order flow is transaction volume that is signed" (i.e. indicating purchases or sales). From an ex ante logical point of view, flow analysis may share similarities with either technical analysis or fundamentalism. This leads to three different views about flow analysis which to some extent compete with 
each other, and which we list in the order of their affinity to the efficient market hypothesis $(\mathrm{EMH})$ :

Position 1 Flow analysis is an expression of limited rational behavior.

In this sense flow analysis is an analogue of technical analysis (see e.g. Shleifer and Summers, 1990). This view relies heavily on the assumption of informational efficiency of markets, according to which any attempt to acquire extra information is futile or even irrational, when costly resources are invested.

Position 2 Flow analysis is a manifestation of rational learning about fundamentals.

This view regards flow analysis as a certain form of fundamental analysis. Conceding time constraints and informational heterogeneity, flow analysis can be viewed as a rational way of trying to detect the results of other participants' fundamental analysis and thus parallels optimal learning from order flow such as in the seminal work of Kyle (1985).

Position 3 Flow analysis provides interim information about short-run price movements but little information about fundamentals.

This view is based on the assumption that the order flow can influence price paths of transactions prices in the short run. Flow analysis is understood as a separate kind of analysis if it aims at forecasting transactions prices from presently executed and planned order flows (see e.g. Ito, Lyons and Melvin, 1998, Covrig and Melvin, 2001). According to this view, flows also contain information about short-term trading objectives or liquidity considerations of other traders that may affect shortterm price movements, but that will not affect medium-term asset prices. Such information is usefully termed semi-fundamental information. 
Unfortunately, at present there is virtually no direct systematic information available about the importance and nature of flow analysis. Because of this lack of knowledge, it seems worthwhile to improve our understanding by conducting a questionnaire survey study among market participants. This study is organized around three questions: is flow analysis an important forecasting tool in real world markets? ${ }^{1}$ Can flow users be related to certain institutional characteristics? And finally, are there beliefs of flow users about FX markets which would reveal their motivation for applying flow analysis?

This study provides several insights: it demonstrates that in addition to fundamental and technical analysis, flow analysis is indeed a major and independent third tool for FX professionals. Furthermore, the use of flow analysis is systematically related to some institutional characteristics and beliefs about the functioning of FX markets. Our results provide varying degrees of support for the three "positions" under review: the most interesting seems to be the affinity with position 3 , that is the view that flow analysis aims at exploiting semi-fundamental information.

The survey approach chosen was developed as a standard methodology to establish market participants' behavior in financial markets. The pioneering work by Shiller (1989) was first applied to foreign exchange markets by Allen and Taylor (1990). The latter thoroughly examined the use of technical analysis in the London FX market which is the reference case for our work (Taylor and Allen, 1992). The same approach was reproduced for Hong Kong based FX dealers by Lui and Mole (1998). Related studies on foreign exchange markets include Menkhoff (1997, 1998), Cheung and Wong (2000), Cheung and Chinn (2001) and Cheung, Chinn and Marsh

\footnotetext{
${ }^{1}$ The purpose of professionals' behavior is to forecast foreign exchange rates and not to explain contemporaneous movements.
} 
(1999). However, to the best of our knowledge, there is no survey study explicitly examining the use of flow analysis in foreign exchange markets.

Our investigation of flow analysis consists of seven steps: Section 2 reviews the literature on possible explanations for the use of flow analysis. Section 3 provides a short description of the data used. In Section 4 the evidence on the importance of flow analysis in the FX market in relation to the two established forms of fundamentalism and chartism is presented. This is followed in Section 5 by an analysis of the question whether flow users can be viewed as a distinct, coherent group of more or less rational people. Section 6 relates flow users to certain characteristics of behavior and Section 7 relates them to beliefs about FX market characteristics. We present our conclusions in Section 8. An appendix describes the survey data in more detail.

\section{A review of possible justifications for flow analysis}

This review reflects the development of arguments which were first modeled in a stock market setting and later adapted to foreign exchange markets. The empirical finance literature largely concentrates on two types of participants in financial markets, rational investors and liquidity or noise traders. Typically, rational investors are viewed as agents who pursue strategies which are optimal, given their knowledge of fundamental information concerning the assets' liquidation values, while liquidity traders' behavior is exogenously determined and either motivated as exogenous hedging demand (e.g. Spiegel and Subrahmanyam, 1992), or even completely irrational behavior with little or no relation to fundamental information which noise traders might actually have. While this approach with two polar types of agents is useful for modeling markets with incomplete revelation of inside information 
through prices (see e.g. Grossman and Stiglitz, 1980, and Hellwig, 1980) and thus for finding solutions to the information paradox, ${ }^{2}$ it may be too rough to understand the details of real world markets and, particularly, the real world processes of price determination.

Consequently, the market microstructure theory building on the seminal paper of Kyle (1985) distinguishes three types of traders: informed investors, market makers and noise traders. ${ }^{3}$ Again, informed traders are viewed as investors with private information about fundamentals, and noise traders trade for exogenous liquidity motives. Market makers, however, can learn some of the insiders' information from observing the aggregate order flow. In fact, because market makers will make inferences from the order flow, insiders will try to conceal their information by trading less aggressively. ${ }^{4}$ In this framework, market makers determine prices as conditional liquidation values based on the information incorporated in the aggregate order flow. Accordingly, market makers do behave fully rationally. Since they do not have access to the proprietary information of insiders they have to deduce it from observing the order flow.

\footnotetext{
${ }^{2}$ The information paradox essentially arises when prices are adequate statistics of the underlying information. As Allen (1981) shows, the price system will generically reveal all the underlying (inside) information when there are more prices (or markets) than sources of uncertainty. If, on the other hand, there are other sources of uncertainty besides prices, the price mechanism will not generally reveal inside information completely. This result has been originally established in markets with investors who receive proprietary information, and noise traders, who trade randomly for exogenous reasons. In such settings the price mechanism reveals the information of insiders only imperfectly, since high prices may e.g. signal good information or merely a high realization of liquidity demand. Partial revelation, however, does not necessarily require the existence of noise traders, and can also occur as a robust feature of equilibrium, for example, when the signal space is sufficiently rich (see Ausubel, 1990).

${ }^{3}$ See, in particular, Admati and Pfleiderer (1988), Spiegel and Subrahmanyam (1992) and Rochet and Vila (1994).

${ }^{4}$ Insiders are typically modelled as risk neutral agents. Because market makers make inferences from the order flow and insiders know about the impact of their trades on market makers' inferences, they tend to trade in "small" amounts, in order to hide behind noise traders. For example, large buying orders relative to the variance of noise trading would be interpreted predominantly as positive information by the market makers, and, thus almost reveal the insider.
} 
Hence, market microstructure theory emphasizes the importance of the informational content of the aggregate order flow. However, information about partial order flows is also useful, as Chowdry and Nanda (1991) show in a multi-market setting, when the order flow is fragmented across markets. Chakrabarti (2000) also provides a model of the FX market where dealers only learn from observing idiosyncratic signals, which could usefully be interpreted as the (local) order-flow. While this literature evidently generally attributes the role of learning from the order flow to market makers only, there are no particular reasons for doing so. It appears natural that market makers' access to information about the order flow is relatively cheap and privileged, but, in principle, there may also be other traders in the market with some knowledge about the order flow which they can profitably exploit.

Accordingly, theory suggests that learning from the order flow may be a rational strategy for traders who do not have access to first hand information of a security's liquidation value, or simply, fundamental information. This view is formulated in our position 2. Position 1, in contrast, views investors or traders relying on flow information simply as liquidity or noise traders.

However, is informational asymmetry about asset fundamentals an important phenomenon in FX markets? While there may be a lot of private information about individual stocks in the markets, it appears that most fundamental information in FX markets is public information. In recent work, Ito, Lyons and Melvin (1998) have presented convincing evidence for the presence of private information in the US\$Yen market. ${ }^{5}$ They argue that even when most fundamental information is public, traders may still possess privileged information about the short-term movements of

\footnotetext{
5 These authors analyse trading patterns before and after the abolition of trading restrictions during lunch time in Tokyo. The observed flattening of the U-shape of intra-day price variability and the reduced variability at the opening of trade cannot be explained on the basis of models with symmetric information and thus suggests the existence of private information.
} 
prices, which they do exploit. For example, traders may have some privileged information about other traders' (aggregate) inventory imbalances, and they then trade on the assumption that those inventories should converge to some long run steady state level. Such information may be price relevant in the interim but irrelevant in the long run. They label such information semi-fundamental private information. To the extent that semi-fundamental private information is relevant during the course of the trading day, the analysis of the order flow can also be informative about such semi-fundamental information (see also Covrig and Melvin, 2001). In other words, given that private information seems to play a role also in FX markets, flow analysis seems a legitimate rational learning mechanism for less informed traders. ${ }^{6}$ In fact, Evans and Lyons (2002) even strongly suggest that order flow contains information that helps to predict exchange rates. In their sample, they can account for $50 \%$ of the variation in the DM/US\$ rate and for about $30 \%$ in the Yen/US\$ rate, which significantly exceeds the mere $10 \%$, which is traditionally accounted for by publicly observable macro aggregates (Meese and Rogoff, 1983; see also Frankel and Rose, 1995, MacDonald, 1995, and Taylor, 1995). This line of reasoning underlies the view expressed in position 3.

Building on this view, one would expect that flow analysis is mainly performed by traders with privileged access to the order fow. Moreover, since it is intended to reveal information about short-term price movements flow analysis should be used especially by agents with immediate market access. Flow analysis should be particularly helpful for smaller traders trying to acquire information about the (aggregate) trading behavior of larger institutions. On the other hand, larger trading institutions might use flow analysis in order to time their trades and minimize the

\footnotetext{
${ }^{6}$ For example, a large fund may decide to sell foreign stocks in a rather illiquid market for pure liquidity reasons. It may take some time for other investors to bid up prices back to their equilibrium
} 
impact of their trades on prices. Moreover, larger fund management institutions might have stronger interests in acquiring direct trading access and timing their trades relative to smaller fund managers. We test these hypotheses explicitly in the analysis below. $^{7}$

Inasmuch as flow analysis reveals more semi-fundamental private information and less fundamental private information, it appears as a less attractive methodology for fund managers with lower trading frequencies. Before these hypotheses are examined, however, the question is whether flows are important for real world decision makers. ${ }^{8}$ We have asked the respective target group.

\section{Methodology and data}

The following analyses are based on the feedback obtained from a questionnaire mailed in June 2001 to professional foreign exchange market participants in Germany, one of the major centers for foreign exchange transactions. ${ }^{9}$ The target group consists of all relevant trading banks and international fund management companies at that time. The relevance of banks in this business was identified with the help of several experienced participants and resulted in 50 institutions. Those 15 institutions which belong to the respective working group in the association of public banks (Bundesverband Öffentlicher Banken) received as many questionnaires as dealers taking their own positions were expected to trade there.

\footnotetext{
values. This "window of opportunity" may be spotted by flow analysis.

7 Hypothesis 3 (below) tests whether flow analysis is more relevant to fund managers or traders. Hypothesis 10 (below) tests for size effects across traders and fund managers separately.

Hypotheses 1 and 2 below test explicitly the significance of flow analysis as an independent source of information.

${ }_{9}$ Germany's market share in the world foreign exchange market is $5.4 \%$ according to the last Bank for International Settlements (2001) survey. To be more exact, the survey of foreign exchange dealers but not that of fund managers - includes the Austrian market, where $10 \%$ of the questionnaires were allocated. This accords with Austria's worldwide market share in FX transactions of $0.5 \%$. More important than the market share is the fact that major national differences have not been identified so far.
} 
Each of the other 35 banks received between two and six questionnaires, according to their size. Regarding fund management companies, all appropriate members of the respective association in Germany (Bundesverband Deutscher InvestmentGesellschaften) were addressed..$^{10}$ Again, between two questionnaires for the small companies and up to six questionnaires for the largest ones were sent.

We received 203 useful responses. This feedback implies an unusually successful response rate of $51.9 \%$. The detailed structure of the mailing of the questionnaires, the respective esponse and further discussion on methodology and data quality are given in the Appendix.

\section{On the importance of flow analysis}

The pre-survey interviews already revealed that market participants would rather rely on three than two independent sources of information, namely, fundamental analysis, technical analysis, and flow analysis. This information seems relevant when professionals are asked about the "information type" they use in substantiating their decision making before taking open positions. If only fundamentalism and chartism were relevant, one might expect the share attracted by flow analysis to be negligible. It is also an implication of position 1 that professionals do not intensively use a tool that requires imperfect markets to a larger extent. To translate this into figures, irrelevant shares for flows-based decision making can be stated in the form of two statistical hypotheses:

H1 The average importance of flows for decision making is low, to be concrete say below $10 \%$, in competition with fundamentals and technical analysis.

\footnotetext{
10 The funds managed are mutual funds and other funds which mostly serve purposes similar to pension funds.
} 
H2 There are no professionals who pay the same or more attention to flows than to fundamentals or technical analysis.

Another hypothesis which can be tested with this data is derived from position 3. If flows provide "semi-fundamental private information", then short-term oriented dealers would use this tool more intensively than longer-term oriented fund managers (see also Section 2):

H3 FX dealers consider flows more important than international fund managers.

The results of the questionnaire are shown in Table 1. The upper Panel A of Table 1 shows the average importance of fundamental, technical and flow analysis, both for all respondents, or separated into FX dealers and international fund managers. ${ }^{11}$ The response of an average weight of $23.5 \%$ given to flows means evidence is rather against hypothesis 1 .

The importance of flows is illustrated in the lower Panel B of Table 1: flow analysis seems relevant for at least three quarters of the fund managers and for an even larger portion of the dealers. Again, hypothesis 2 is clearly rejected. Flows are an important source of information for FX professionals; for a major group they are more important than either fundamentals or technical analysis, or even both of them together.

Finally, one can see from the figures for dealers and fund managers that in accordance with position 3 the latter rely significantly less on flow information. ${ }^{12}$ Thus, hypothesis 3 can not be statistically rejected.

An interesting side-aspect of the results of Table 1 is that fundamentals and charts appear as more important than flows if one considers the aggregates across

\footnotetext{
11 The fundamentals include political events which are determinants of the country risk premium. Moreover, political changes may influence the course of economic policy making and thus the expected values of economic fundamentals.
} 
all respondents. This observation seems to justify the limitation to these two "traditional" categories in earlier studies. Furthermore, it leads to the consideration whether the use of flows could be related to the use of fundamentals or technical analysis. From the viewpoint of position 1, the application of both technical and flow analysis should be interpreted as boundedly rational behavior. One could thus expect a positive correlation between both information types, as they are motivated by the same type of user. At least from this viewpoint, the share of technical analysis in the sum of non-flow analysis should increase. In contrast, position 2, which states a familiarity of flow analysis with fundamental analysis, would claim the opposite hypothesis; the expected positive correlation of flow use and fundamental analysis implies a negative relation between flows and technical analysis and thus a negative sign in hypothesis 4. If, however, flow analysis is rather a different type of information, such as claimed by position 3, then there would be no close relationship to the use of both of the other types of information. The implication is, then, the intensity of flow use and the other kinds of analysis are independent of each other. These considerations lead to three competing expectations regarding the sign of the relation expressed in hypothesis 4 which is formulated from the position of position 1:

H4 The more intensive use of flow analysis is positively related to a more intensive use of technical analysis as opposed to fundamental analysis.

The results are plotted in Figure 1. The figure classifies all respondents according to the intensity of use of flow analysis. As the second piece of information, the share of technical analysis in the sum of technical plus fundamental analysis is plotted as a line for groups of respondents. We form groups of respondents for every ten percentage points of flow use, starting for the first group from $0 \%$ to below $10 \%$,

\footnotetext{
12 Significance tests in this paper are always non-parametric as the underlying data cannot be described by a normal distribution.
} 
then from $10 \%$ to below $20 \%$ and going up to $60 \%$ and more. Hypothesis 4 states that the line in Fgure 1 should have a positive slope. It can be seen, however, that with an increasing share of flow analysis the two other forms are decreasing in similar fashion. Thus, neither hypothesis 4 nor the implication of position 2 is supported by the evidence. It is position 3, that flow analysis is an independent kind of information, which best explains Figure 1 .

In summary, Section 3 provides clear evidence for the relevance of flows in foreign exchange markets as an independent source of information. It further supports the interpretation of position 3 and rejects the implications of positions 1 and 2. What can be said about the characteristics of the flow users? Are there indications of rationality or institutional differences?

\section{On institutional characteristics of flow users}

From an efficient markets perspective, representing an interpretation of flow analysis as formulated in position 1 , one may argue that the institutional characteristics of FX markets, such as high liquidity and true international trading, do not allow sufficient room for reasonable flow analysis: shocks will be absorbed quickly, as will large orders and important news. A consequence of this view is that those who pay more attention to flow analysis can be seen as less rational market participants.

As rationality can not be observed directly, we search for indicators which should be correlated with rational behavior (see also Menkhoff, 1997). In this sense, it may be expected that those who have a better education, and, thus, in principle, better prerequisites to distinguish useful from noisy information, behave more rationally than others. Furthermore, efficient markets can be expected to differentiate 
over time between more or less successful participants. If one accepts that market success is related to rationality, then success indicators, such as pure survival in the market, proxied by age, and career progress, proxied by reaching a superior position, indicate rationality. ${ }^{13}$ This leads to the following hypotheses to be confronted with survey data:

H5 A more intensive use of flow analysis is negatively related to a higher degree of education.

H6 A more intensive use of flow analysis is negatively related to a higher age.

H7 A more intensive use of flow analysis is negatively related to a superior position.

The results of respective rank correlations are given in Panel A of Table 2. The sign of the coefficients is mostly negative, i.e. supporting the hypotheses and thus position 1. However, there is some heterogeneity and mostly insignificance. Regarding the characteristics education and age, the sign is different for dealers and fund managers. Interestingly, the use of flow analysis has a more rational "appeal" among fund managers. Only the characteristic "position" provides similar results for both groups of agents: higher position reduces the likelihood of using flow analysis. Concentrating on statistically significant coefficients, hypothesis 5 seems to be rather rejected by the survey and hypothesis 6 rather supported. Note, however, that the more intensive use of flows by younger FX dealers could also have a rational motivation, if flow analysis has true value - as stated by positions 2 and 3 - and if flow analysis is a newer kind of analysis which is therefore more easily grasped by new market entrants.

To check the robustness of these results, the same questions were investigated by concentrating on the characteristics of intensive flow users rather than others. For

\footnotetext{
13 Even if one is not prepared to accept our interpretation of education, age and position as meaningful indicators of rationality, at least the indicator education is statistically related to the use of
} 
this purpose, those 35 respondents who use flows as preferred information, and in a second analysis those 90 respondents who use flows at least as a second most important source of information (see Table 2), were compared to the others by applying Chi-square tests. Results confirm the earlier correlation analyses and are thus not reported here.

In addition to these characteristics of FX professionals, further institutional characteristics have been related to the use of flow analysis. Focusing on FX dealers, a referee has claimed that proprietary traders of larger banks (with huge customer business) in particular rely on flow analysis. We have examined this idea which best fits the viewpoint of position 3 - using a step by step approach, as our limited database does not really allow for grouping respondents into the required fine cluster. Thus, the single elements of this idea are correlated with the use of flows leading to three hypotheses:

H8 Proprietary dealers use flow analysis more than other FX dealers.

H9 The share of customer business of a bank is positively related to the intensity of flow use of the dealers in this bank.

A third analysis in this respect also draws on the considerations in Section 2 and examines the possible relation of the use of flows and the institutions' size in which the respondents work. Whereas on the basis of position 1 one would not expect any systematic relationship, the following implications are derived from positions 2 and 3: the incentive in smaller institutions may be stronger to watch trading flows with the aim of drawing inferences about trading activities of better informed, larger institutions which can invest in extensive fundamental research (position 2). On the other hand, if there really is semi-fundamental private information in the FX market, then the bigger institutions, measured via larger FX transactions' 
volume and larger international funds under management respectively, have a better chance of profiting from flow analysis (position 3). Thus, both positions compete directly with each other and can be tested by a single hypothesis which is formulated from position 3, to argue consistently:

H10 A more intensive use of flow analysis is positively related to the size of a trading or fund management institution.

The evidence in Panel B of Table 2 on hypotheses 8 and 9 provides clear information that neither the job of proprietary versus liquidity dealer nor the share of

customer business indicates a more intensive use of flows. However, size is significantly related to the use of flow analysis for fund managers and clearly positively related for FX dealers, as can be seen from Panel C in Table 2. This implies evidence in favor of hypothesis 10 and hence supports position 3 relative to position 2.

In summary, position 1, which regards flow analysis as a sign of less rational behavior, receives some empirical support. There is also slight evidence that the role of flow analysis may be related to indicators of rationality in the field of international fund management, which states an affinity towards position 3 . Finally, the more intensive use of flows in larger institutions is expected from the viewpoint of position 3 but not from that of position 2 .

\section{On the individual behavior of flow users}

The last section has shown that flow users share some institutional characteristics. However, most empirical relations have not been tight, which leaves a lot of room for other possible influences, e.g. individual behavior. Seen from position 1, one would expect that reliance of flow analysis is - analogously to the use 
of technical analysis (see Taylor and Allen, 1992) - positively related to a shorter forecasting horizon. Position 2, however, reflects no clear view on this relation as the learning process about fundamentals may be short-term oriented while the focus on fundamentals requires a longer horizon. Position 3 finally proposes a very short-term horizon for flow analysis as the value of this semi-fundamental information for speculative purposes quickly disappears over time. ${ }^{14}$ Hypothesis 11 is formulated from the viewpoint of positions 1 and 3 :

H11 Flow analysis is more intensively used at shorter forecasting horizons.

The responses presented in the form of rank correlations in Panel A of Table 3 clearly support this hypothesis. Whereas position 2 is not supported by this result, both positions 1 and 3 fit the result but offer very different explanations. Thus, additional information is required for a more far reaching judgment about the reasons for this short-term oriented forecasting horizon. It would be of particular importance to know which sources of information are highly regarded by flow users. Different positions lead us to expect different things: position 1 leads us to expect that less fundamentally oriented sources of information are important for flow users, such as telephone conversations with other market participants, or large, own customer deals; position 2, with its affinity towards fundamental analysis, suggests that a combination of fundamental information and analyses, e.g. interest rates or in-house produced analyses, with channels gaining possible informational advantage, such as telephone talks is favored. Finally, position 3 suggests a primary focus on customer deals. The respective hypothesis 12 is somewhat loosely formulated from the viewpoint of position 1 :

\footnotetext{
${ }^{14}$ This does not contradict the finding that the horizon over which flow information included in prices can affect exchange rates may be considerably longer (see e.g. Evans and Lyons, 2002).
} 
H12 The more intensive use of flow analysis is positively related to "irrelevant" sources of information, such as talks and customer deals, and negatively related to fundamental information, such as interest rates.

The answers of respondents to the respective questions are documented in Panel B of Table 3. This information allows a discrimination between the three competing positions: the missing link of talks with flow analysis is inconsistent with position 1. The insignificance or even unimportance of some fundamental sources of information for flow users is inconsistent with position 2. Position 3 conforms best with the evidence since own customer deals are seen as a competitive advantage. It is thus only one item that stands out as the core and specific source of flow users, which is large, own customer deals. How do market participants themselves view the functioning of the market?

\section{On the flow users' beliefs about FX markets}

This last empirical section aims at achieving a better understanding of the beliefs of market professionals about the functioning of $\mathrm{FX}$ markets that flow users may have in common and may distinguish them from those who use flows less. If there are some "shared beliefs", this might point towards the users' motivation and thus indicate the relevance of positions 1 to 3 .

It is well known that according to many market participants psychological influences play a major role in defining exchange rate prices (Taylor and Allen, 1992, Cheung and Wong, 2000). From the viewpoint of position 1, the less rational behavior of flow users may be indicated in this belief. This leads to hypothesis 13 .

H13 A more intensive use of flow analysis is positively related to a stronger belief in the importance of psychological factors on prices. 
As the importance of psychological factors necessarily rivals the influence from fundamentals, position 2, which relates the use of flows to gaining fundamental information, would better fit with a rejection of hypothesis 13 . Further evidence on the relevance of positions 2 and 3 can be gained from additional statements. Thus it is a necessary condition for learning from better informed investors that the revelation of news in FX prices takes time. The more time is needed for this process, the better the chances are to profit from fow analysis. The respective hypothesis is formulated as follows.

H14 A more intensive use of flow analysis is positively related to a lengthier period of processing fundamental information.

The third position, emphasizing market imperfections in the trading process, seems to imply that larger market participants could have an influence on prices. The more important large market institutions are seen to be for the price discovery process, the more rational it becomes to apply flow analysis:

H15 A more intensive use of flow analysis is positively related to a higher attributed influence by large market participants on prices.

The result of the rank correlations is given in Table 4. As the answers on the respective statements range between 1 for complete agreement and 6 for complete disagreement (logically similar in the case of hypothesis 14), rejection of the hypotheses requires a statistically positive sign in the correlation. In fact, however, the signs are mostly negative, indicating some support for the hypotheses. At a more detailed level, some remarkable differences become evident.

The test of hypothesis 13 does not provide any significant result. Hypothesis 14 is clearly rejected by fund managers, indicating support for positions 2 and 3 . Only hypothesis 15 receives high statistical significance and identical signs for both 
subgroups, strengthening the claim that the use of flow analysis is related to market imperfections. This interpretation is substantiated by a comparison of the subgroup of respondents that assign first preference for flow analysis with others, as preferred flow users' answers are only significantly different with respect to hypothesis 15 . These results have some implication for the relevance of the three competing positions: the motivation of flow users as revealed by the survey does not seem to fit well with the idea of position 1, but correspond more with position 2 and best with position 3 .

From a methodological point of view it should be noted that Section 7 presents flow users' opinions, i.e. the views that they have on FX markets. When they see a major influence of market makers, for example, it makes sense to apply flow analysis but it does not prove that market makers are really important. On the other hand it would be surprising if successful professionals were handicapped by a systematic misunderstanding of real market processes. ${ }^{15}$

\section{Conclusions}

Flow analysis in foreign exchange markets has not been a subject of systematic examination so far. In this respect it shares the fate of technical analysis, which was also quite neglected until a few years ago when Allen and Taylor (1990) conducted their survey. Compared to the wide area of anecdotal and accidental information, our questionnaire establishes better substantiated knowledge in two fields, i.e. regarding on the one hand the importance of flow analysis and on the other, the appropriate understanding of the nature of flow analysis as reflected by three competing positions. The importance of flows may be highlighted by two facts:

\footnotetext{
${ }^{15}$ See also Section 4 on this.
} 
?? First, it becomes obvious that there is a third form of analysis in the market besides fundamental and technical analysis. In the group of respondents, about every second FX dealer and every third fund manager allocated $25 \%$ or more of information used to flow analysis.

?? Second, the relationship with the other two forms of market analysis shows that flow analysis is neither closely related to a preference for "fundamentalism" or "chartism", nor is it a substitute for either of them: it rather represents an independent third form of analysis relevant for professionals.

The survey results have also shed some light on our understanding of the role of flow analysis in foreign exchange markets. Several hypotheses have been tested revealing evidence on the explanatory power of three competing views. The results are compiled in summarized form in Table 5. They provide a clear picture of the explanatory power of three competing positions:

?? Flow analysis does not seem to be basically used as a tool to learn about the fundamental information of others, as claimed in position 2.

?? Moreover, the use of flow analysis does not appear to be clearly related to indicators of less rational behavior, thus slightly opposing the view of efficient markets, as stated in position 1 .

?? However, the evidence seems to accord best with position 3 . This is the view that flow analysis aims at exploiting semi-fundamental private information. 


\section{Acknowledgements}

We would like to thank Richard Lyons, Ronald MacDonald and two anonymous referees for very useful comments and Michael Frömmel and Torben Lütje for excellent research assistance.

\section{Appendix on methodology and data quality}

This appendix describes in more detail the methodology of the questionnaire survey and discusses issues of controlling data quality. An important aspect of the latter is a comparison of the actual survey results with those of an earlier conducted survey.

The different response rates presented in Table 6 can be explained due to differences in the way each group was approached. The best response rate was observed from members of the association, a direct result of the association's helpful assistance, consisting of mailing the survey, collecting it, and performing intensive follow-ups to improve the response. Regarding the other banks, all apparent nonrespondents were contacted by mail or telephone, often several times, in an attempt to convince them to cooperate. The lower response rate for fund managers is a consequence of a comparatively lower degree of effort: only some selective phone calls were made to find out whether there might be systematic reasons for nonresponse - no systematic reasons were detected.

As we also use data from an earlier survey questionnaire (1992) which was, from a methodological standpoint, carried out in the same way (for more details see 
Menkhoff, 1998), it is interesting to look at differences. ${ }^{16}$ First, distinctly fewer banks were addressed in 2001 reflecting the ongoing process of mergers, removal of FX business to London, and, finally, a more precise elimination of banks which intermediate customer deals but do not take own positions. Second, the larger number of fund management companies in the recent survey shows the rising importance of capital markets and in particular fund business in Germany. Third, the even better response rate - up from $41.3 \%$ - has two origins: more effort in contacting non-responding "other banks" and a promise to reward respondents with feedback on the results of the survey.

Several ways were applied to ensure the quality of the survey. This started with a phase of intensive interviewing prior to mailing and a pretest of the questionnaire to ensure appropriate issues and wording. The incoming questionnaires were strictly anonymous but respondents did not seem to care too much about this as only some used the suggested possibility to split their response into one anonymous mail for the questionnaire and another mail ordering the promised feedback. The usually fully filled -out questionnaires indicate adequate presentation of the items.

As a referee remarks, a potential problem could arise in the question whether the core persons in the dealing departments really responded or whether the questionnaires were passed on to less decisive, e.g. supporting, staff. This can never be ruled out when using an anonymous questionnaire survey. We are confident, however, for three reasons: first, the senior persons answer similarly to the less senior ones (see Section 5). Second, many phone conversations with trading departments gave the impression that we had reached the target group of dealers who take positions in own responsibility. Third, the two channels of distributing the

${ }^{16}$ The exact date of the survey was largely arbitrary and was not supposed to cover any extraordinary events. On the contrary and by coincidence, the turbulent EMS crisis started on 14. September 1992, 
questionnaire, where in the one case the association may provide an incentive to cooperate, produced very similar results.

An important methodological objective of a survey questionnaire is to realize a representative response. However, this quality indicator cannot be checked strictly as no statistical survey of the total population is available. It is therefore warranted to realize a high response rate and economically sensible characteristics of the responses. Regarding the response rate, our survey attained a result matched among the several studies in this field mentioned above only by Taylor and Allen (1992). They received feedback from $60 \%$ of the chief dealers addressed. In addition, we had the advantage of being able to use the survey of the members of the association of public banks as a kind of benchmark as originally intended and come close to a full coverage with a response rate of $73.7 \%$. Statistical comparison of the two channels for distributing the questionnaires to foreign exchange dealers reveals no differences indicating a distortion of the private banks' sample.

Moreover, the recent survey can be compared to the earlier study and to studies in other countries. Regarding the 1992-study a few structural characteristics of respondents have changed in a systematic manner. In line with growing markets, volumes asked for have gone up. Furthermore, the average age of FX dealers has increased as can be expected for a maturing "industry", whereas the average age in the boom market of fund management has decreased. Regarding the comparison with other survey studies, our results do not contradict earlier findings, and differences can be reasonably explained.

Finally, in our work the question arose whether the use of flow analysis shows any systematic change over time. This issue can be analyzed for the questions which have been asked in both similar surveys, in 1992 and 2001. Seen from a 
methodological point of view, it could seem reassuring if the earlier results were to be confirmed, but, since markets tend to develop over time, it would perhaps be even more appropriate if a certain pattern of change were to be identified. One referee suggested, for example, that the importance of flow analysis should have ncreased during the 1990s.

A comparison of the two studies indeed confirms this suggestion. We have found that the use of flow analysis has gained relevance in relation to technical analysis and in particular relative to fundamental analysis. Further recognizable changes include a weakening of the former strong relation of flow use with lower education and with important psychology. Another stronger change is now the clear relation of flow use with market imperfection. A complete list of all changes of significant relations between the two surveys is listed in Table 7. This confirms the briefly sketched pattern that, while position 1 , giving flow analysis a less rational appeal, loses ground in the face of empirical evidence, position 3, stressing the semifundamental character of flow analysis, rather gains ground. This move accentuates the already clear picture based on the earlier data documented in the working paper version (see Gehrig and Menkhoff, 2001). It is further supported by the additional evidence drawn from the new questions exclusively asked in the recent survey. 


\section{References}

Admati, A., Pfleiderer, P., 1988. A theory of intraday patterns: volume and price variability. Review of Financial Studies 1, 3-40.

Allen, B., 1981. Generic existence of completely revealing equilibria for economies with uncertainty when prices convey information. Econometrica 49, 11731199.

Allen, H., Taylor, M.P., 1990. Charts, noise and fundamentals in the London foreign exchange market. Economic Journal 100 (Supplement), 49-59.

Ausubel, L., 1990. Insider trading in a rational expectations economy. American Economic Review 80, 1022-1041.

Bank for International Settlements, 2001. Triennial central bank survey of foreign exchange and derivatives market activity 2001: preliminary global data. 9 October 2001, Basel.

Cai, J., Cheung, Y.-L., Lee, R.S.K., Melvin, M., 2001. "Once-in-a-generation" Yen volatility in 1998: fundamentals, intervention, and order flow. Journal of International Money and Finance 20, 327-347.

Chakrabarti, R., 2000. Just another day in the inter-bank foreign exchange market. Journal of Financial Economics 56, 29-64.

Cheung, Y.-W., Chinn, M.D., 2001. Currency traders and exchange rate dynamics: a survey of the US market. Journal of International Money and Finance 20, 439-471.

Cheung, Y.-W., Chinn, M.D., Marsh, I.W., 1999. How do UK-based foreign exchange dealers think their market operates?. CEPR Discussion Paper, No.2230. 
Cheung, Y.-W., Wong, C.Y.-P., 2000. A survey of market practitioners' views on exchange rate dynamics. Journal of International Economics 51, 401-423.

Chowdry, B., Nanda, V., 1991. Multimarket trading and market liquidity. Review of Financial Studies 4, 483-511.

Covrig, V., Melvin, M., 2001. Asymmetric information and price discovery in the FX market: does Tokyo know more about the Yen?. Journal of Empirical Finance, forthcoming.

Evans, M.D.D., 2001. FX trading and exchange rate dynamics. NBER Working Paper, No. 8116.

Evans, M.D.D., Lyons, R.K., 2002. Order flow and exchange rate dynamics. Journal of Political Economy 110, 170-180.

Frankel, J.A., Rose, A.K., 1995. Empirical research on nominal exchange rates. In: Grossmann, G., Rogoff, K. (Eds.), Handbook of International Economics, Vol.III. North-Holland, Amsterdam et al., 1689-1729.

Gehrig, T., Menkhoff, L., 2001. The use of flow analysis in foreign exchange: exploratory evidence. Centre for Financial Markets Research Discussion Paper, No.18, University of Strathclyde.

Goodhart, C., 1988. The foreign exchange market: a random walk with a dragging anchor. Economica 55, 437-460.

Grossman, S., Stiglitz, J., 1980. On the impossibility of informationally efficient markets. American Economic Review 70, 393-408.

Hellwig, M.F., 1980. On the aggregation of information in complete markets. Journal of Economic Theory 22, 477-498.

Ito, T., Lyons, R.K., Melvin, M., 1998. Is there private information in the FX market? The Tokyo experiment. Journal of Finance 80, 1111-1130. 
Kyle, P., 1985. Continuous auctions and insider trading. Econometrica 53, 13151336.

Lui, Y.-H., Mole, D., 1998. The use of fundamental and technical analysis by foreign exchange dealers: Hong Kong evidence. Journal of International Money and Finance 17, 535-545.

Lyons, R.K., 1995. Tests of microstructural hypotheses in the foreign exchange market. Journal of Financial Economics 39, 321-351.

Lyons, R.K., 1998. Profits and position control: a week of FX trading. Journal of International Money and Finance 17, 97-115.

Lyons, R.K., 2001. The microstructure approach to exchange rates. MIT Press, Cambridge.

MacDonald, R., 1995. Long-run exchange rate modeling, a survey of the recent evidence. IMF Staff Papers 42, 437-489.

Meese, R., Rogoff, K., 1983. Empirical exchange rate models of the seventies. Journal of International Economics 14, 3-24.

Menkhoff, L., 1997. Examining the use of technical currency analysis. International Journal of Finance and Economics 2, 307-318.

Menkhoff, L., 1998. The noise trading approach - questionnaire evidence from foreign exchange. Journal of International Money and Finance 17, 547564.

Osler, C.L., 1998. Short-term speculators and the puzzling behaviour of exchange rates. Journal of International Economics 45, 37-57.

Rochet, J.-C., Vila, J.-L., 1994. Insider trading without normality. Review of Economic Studies 61, 131-152.

Shiller, R.J., 1989. Market Volatility. MIT Press, Cambridge, London. 
Shleifer, A., Summers, L.H., 1990. The noise trader approach to finance. Journal of Economic Perspectives 4, 19-33.

Spiegel, M., Subrahmanyam, A., 1992. Informed speculation and hedging in a noncompetitive securities market. Review of Financial Studies 5, 307-329.

Taylor, M.P., 1995. Exchange rate economics. Journal of Economic Literature 33, 1347.

Taylor, M.P., Allen, H., 1992. The Use of technical analysis in the foreign exchange market. Journal of International Money and Finance 11, 304-314. 
TABLE 1. On the importance of flow analysis

Question: "Please evaluate the importance of the three following information types for your typical decision making, by distributing a total of 100 points. For information types which you do not use, please give 0 points."

... Fundamentals (economic, political)

... Technical analysis (charts, quantitative methods)

... Flows (who is doing what, which customer orders are existing)

PANEL A: The average importance of different information types

All FX dealers Fund Test for

respondents managers significant

$\mathrm{n}$ in $\%^{1} \quad \mathrm{n}$ in $\%^{1} \quad \mathrm{n}$ in $\%^{1} \quad \mathrm{~W}$

Fundamentals

$\begin{array}{llll}201 & 36.3 & 144 & 32.4\end{array}$

$57 \quad 46.2$

$-4.108^{\star \star *}$

Technical analysis

$\begin{array}{llll}201 & 40.2 & 144 & 41.4\end{array}$

$\begin{array}{ll}57 & 37.0\end{array}$

$-1.696^{*}$

Flows

$\begin{array}{llll}201 & 23.5 & 144 & 26.2\end{array}$

$57 \quad 16.8$

$-3.080^{* * *}$

PANEL B: Share of persons with following characteristics of use of flows

\begin{tabular}{rrrrrrc}
\multicolumn{1}{c}{$\begin{array}{c}\text { All } \\
\text { respondents }\end{array}$} & FX dealers & \multicolumn{2}{c}{$\begin{array}{c}\text { Fund } \\
\text { managers }\end{array}$} & $\begin{array}{c}\text { Test for } \\
\text { significant } \\
\text { differences }\end{array}$ \\
$\mathrm{n}$ & in $\%^{3}$ & $\mathrm{n}$ & in $\%^{3}$ & $\mathrm{n}$ & in $\%^{3}$ & $?^{2}$ \\
167 & 83.1 & 124 & 86.1 & 43 & 75.4 & $3.310^{*}$ \\
163 & 81.1 & 121 & 84.0 & 42 & 73.7 & $2.850^{*}$ \\
90 & 44.8 & 71 & 49.3 & 19 & 33.3 & $4.213^{\star *}$ \\
35 & 17.7 & 32 & 22.1 & 3 & 5.2 & $8.289^{* * *}$
\end{tabular}

Note: The number of cases may be different from the total sample due to incomplete responses.

1 Average weight of information type

2 Wilcoxon rank sum test and Chi square test respectively, null hypothesis: use of information

types is identically distributed for both groups, i.e. FX dealers and fund managers.

3 Share of total sample

Stars refer to level of significance, ${ }^{*}: 10$ per cent, ${ }^{* *}: 5$ per cent, ${ }^{* * *}: 1$ per cent 
FIGURE 1. The ratio of fundamental to technical analysis depending on the use of flow analysis

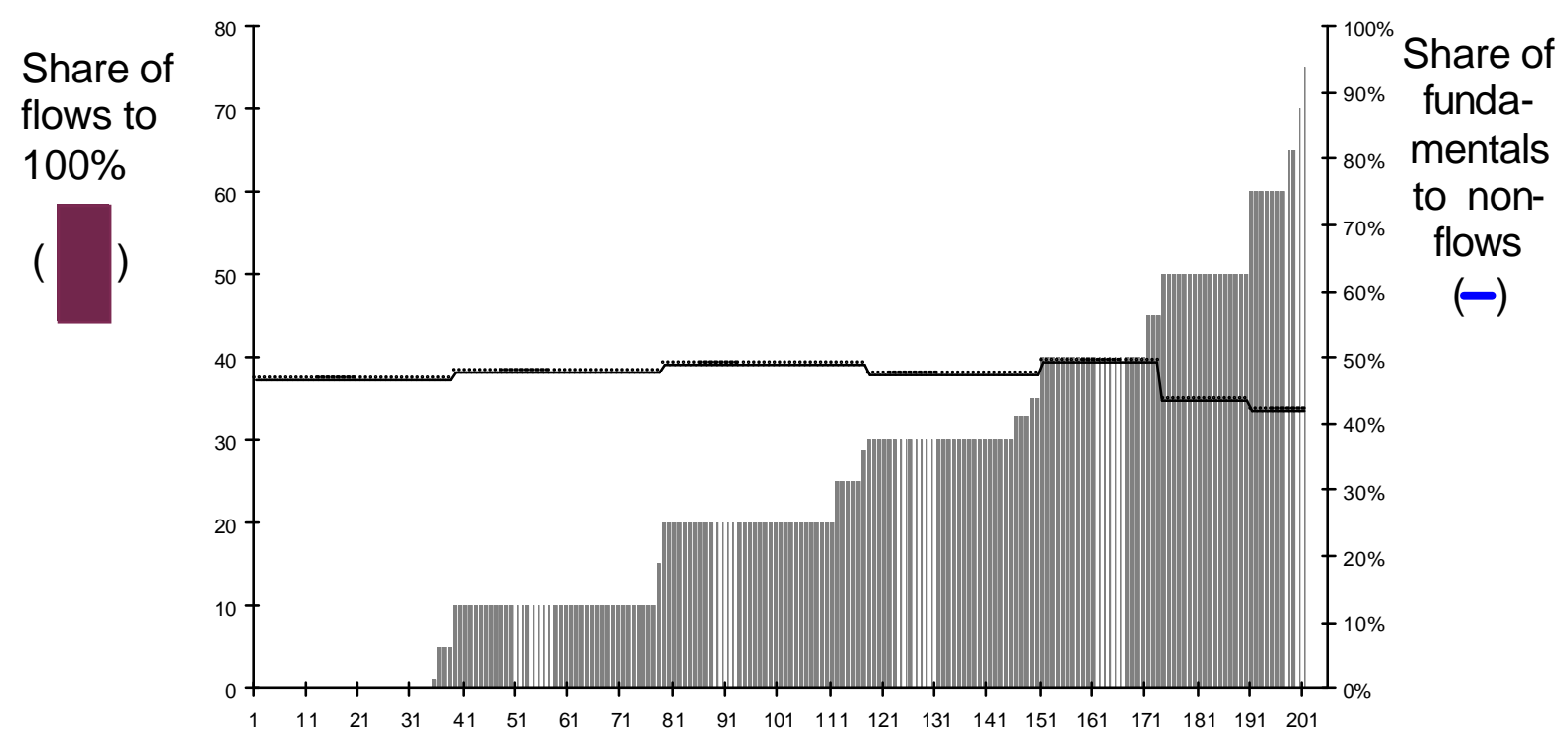

All respondents in order of the intensity of using flows 
TABLE 2. Information on flow use and institutional characteristics

PANEL A: Rank correlations of flow use and users characteristics

$\begin{array}{cc}\text { All } & \text { FX dealers } \\ \text { respondents } & \end{array}$

\begin{tabular}{lccc} 
Higher degree of education & -0.067 & -0.010 & $0.297^{* *}$ \\
(4 categories) & $(0.352)$ & $(0.911)$ & $(0.025)$ \\
& {$[196]$} & {$[144]$} & {$[57]$} \\
Higher age (5 categories) & -0.088 & $-0.147^{*}$ & 0.027 \\
& $(0.214)$ & $(0.078)$ & $(0.842)$ \\
& {$[201]$} & {$[144]$} & {$[57]$} \\
Superior position & -0.022 & -0.045 & -0.045 \\
(2 categories) & $(0.726)$ & $(0.595)$ & $(0.741)$ \\
& {$[200]$} & {$[144]$} & {$[56]$} \\
\hline
\end{tabular}

PANEL B: Rank correlation of flow use and share of customer business

$\begin{array}{ccc}\text { All FX dealers } & \begin{array}{c}\text { Liquidity } \\ \text { dealers }\end{array} & \begin{array}{c}\text { Proprietary } \\ \text { dealers }\end{array} \\ -0.001 & -0.016 & 0.121 \\ (0.993) & (0.907) & (0.323) \\ {[139]} & {[53]} & {[69]}\end{array}$

PANEL C: Rank correlation of flow use and institution size (3 categories)

$\begin{array}{cc}\text { FX dealers } & \text { Fund managers } \\ 0.134 & 0.351^{* * *} \\ (0.117) & (0.009) \\ {[138]} & {[55]}\end{array}$

Coefficient of rank correlation, significance ( $p$-value) in parenthesis and number of responses in squared brackets

Stars refer to level of significance, ${ }^{*}: 10$ per cent, ${ }^{* *}: 5$ per cent. ${ }^{* * *}: 1$ per cent 
TABLE 3. Information on flow use and individual behavior

\begin{tabular}{|c|c|c|c|}
\hline \multicolumn{4}{|c|}{ PANEL A: Rank correlation of flow use and individual forecasting horizon } \\
\hline \multirow[t]{3}{*}{ Question: } & \multicolumn{3}{|c|}{$\begin{array}{l}\text { "How far in advance do you take into account possible influences on the exchange rates } \\
\text { when opening a position? } \\
\text { Please, only one answer:" [1: intra-day, } \ldots, 6:>12 \text { months] }\end{array}$} \\
\hline & All respondents & FX dealers & Fund managers \\
\hline & $\begin{array}{c}-0.313^{\star * *} \\
(0.000) \\
{[201]}\end{array}$ & $\begin{array}{c}-0.299^{* * *} \\
(0.000) \\
{[144]}\end{array}$ & $\begin{array}{c}-0.112 \\
(0.407) \\
{[57]}\end{array}$ \\
\hline
\end{tabular}

PANEL B: Rank correlation of flow use and sources of information

Question: "How important are for your decision-making the following sources of information? Please, evaluate its importance with a number from 1 to $6: "$ [1: very important, ..., 6 : completely unimportant]

FX dealers Fund managers

\begin{tabular}{lcc} 
Direct (telephone) & -0.022 & -0.146 \\
talks with other & $(0.795)$ & $(0.277)$ \\
market participants & {$[142]$} & {$[57]$} \\
Level of money & 0.055 & $0.282^{* *}$ \\
market rates & $(0.520)$ & $(0.035)$ \\
& {$[137]$} & {$[56]$} \\
Inhouse produced & -0.026 & -0.215 \\
analyses & $(0.758)$ & $(0.112)$ \\
& {$[139]$} & {$[56]$} \\
Large, own customer & $-0.428^{* * *}$ & - \\
deals & $(0.000)$ & \\
& {$[139]$} & \\
\hline
\end{tabular}

Coefficient of rank correlation, significance ( $p$-value) in parenthesis and number of responses in squared brackets

Stars refer to level of significance, ${ }^{*}: 10$ per cent, ${ }^{* *}: 5$ per cent. ${ }^{* * *}: 1$ per cent 
TABLE 4. Rank correlations of flow use and beliefs about FX markets

Question: "How much importance do fundamentals and psychology have for exchange rate movements?"

() People are not machines; thus psychology is clearly more important than fundamentals.

[1: agree completely, ..., 6: disagree completely]

Question: "How long does it sometimes need that fundamentals succeed in foreign exchange markets?"

[1: always immediately, ..., 6: > 12 months]

Question: "Do you belief that big market participants have an influence on price formation?" () Yes, they can "make" exchange rates for a while via own position taking or customer orders.

[1: agree completely, ..., 6: disagree completely]

\begin{tabular}{lccc}
\hline & All respondents & $\begin{array}{c}\text { FX } \\
\text { dealers }\end{array}$ & $\begin{array}{c}\text { Fund } \\
\text { managers }\end{array}$ \\
Higher importance of psychological & -0.008 & 0.073 & -0.105 \\
factors on prices & $(0.910)$ & $(0.383)$ & $(0.435)$ \\
& {$[200]$} & {$[143]$} & {$[57]$} \\
Longer time of fundamentals & 0.017 & -0.023 & $0.268^{* *}$ \\
information processing & $(0.810)$ & $(0.795)$ & $(0.044)$ \\
& {$[191]$} & {$[134]$} & {$[57]$} \\
Higher importance of market & $-0.193^{* * *}$ & -0.132 & -0.76 \\
makers on prices & $(0.006)$ & $(0.114)$ & $(0.575)$ \\
& {$[201]$} & {$[144]$} & {$[57]$} \\
\hline
\end{tabular}

Coefficient of rank correlation, significance ( $p$-value) in parenthesis and number of responses in squared brackets

Stars refer to level of significance, ${ }^{*}: 10$ per cent, ${ }^{* *}: 5$ per cent. ${ }^{* * *}: 1$ per cent 
TABLE 5. Evidence from hypothesis tests regarding positions 1 to 3

\begin{tabular}{|c|c|c|c|c|}
\hline No. & $\begin{array}{l}\text { Hypotheses } \\
\text { Description }\end{array}$ & $\begin{array}{l}\text { Position } 1 \\
\text { flow analysis } \\
\text { as sign of } \\
\text { non-optimal } \\
\text { behavior }\end{array}$ & $\begin{array}{l}\text { Position } 2 \\
\text { flow analysis as } \\
\text { instrument to } \\
\text { learn about fun- } \\
\text { damental news }\end{array}$ & $\begin{array}{l}\text { Position } 3 \\
\text { flow analysis as in- } \\
\text { strument to exploit } \\
\text { semifundamental } \\
\text { private information }\end{array}$ \\
\hline 1 & Absolute importance & - & & \\
\hline 2 & Relative importance & - & & \\
\hline 3 & Subgroup importance & & & + \\
\hline 4 & $\begin{array}{l}\text { Correlation with other } \\
\text { information types }\end{array}$ & - & - & + \\
\hline 5 & Relation to education & - & & + \\
\hline 6 & Relation to age & + & & \\
\hline 7 & Relation to position & & & \\
\hline 8 & $\begin{array}{l}\text { Relation to proprietary } \\
\text { dealers }\end{array}$ & & & \\
\hline 9 & $\begin{array}{l}\text { Relation to share of } \\
\text { customer business }\end{array}$ & & & \\
\hline 10 & $\begin{array}{l}\text { Relation to company } \\
\text { size }\end{array}$ & & - & + \\
\hline 11 & $\begin{array}{l}\text { Relation to forecasting } \\
\text { horizon }\end{array}$ & + & $(-)$ & + \\
\hline 12 & $\begin{array}{l}\text { Relation to sources of } \\
\text { information }\end{array}$ & - & - & + \\
\hline 13 & $\begin{array}{l}\text { Belief in psychological } \\
\text { factors }\end{array}$ & & & \\
\hline 14 & $\begin{array}{l}\text { Belief in longer time } \\
\text { for information pro- } \\
\text { cessing }\end{array}$ & & + & + \\
\hline 15 & $\begin{array}{l}\text { Belief in importance of } \\
\text { large market partici- } \\
\text { pants }\end{array}$ & & & + \\
\hline
\end{tabular}


TABLE 6. Coverage and response rates

\begin{tabular}{|c|c|c|c|c|c|c|c|}
\hline \multirow[b]{2}{*}{ Institutions } & \multirow[b]{2}{*}{ Addressed } & \multicolumn{2}{|c|}{ Addressed } & \multicolumn{2}{|c|}{ Response } & \multicolumn{2}{|c|}{ Response rate } \\
\hline & & Inst. & Quest. & Inst. & Quest. & Inst. & Quest. \\
\hline Banks & Directly & 35 & 112 & 28 & 72 & $80.0 \%$ & $64.3 \%$ \\
\hline Banks & $\begin{array}{l}\text { via } \\
\text { Association }\end{array}$ & 15 & 99 & 14 & 73 & $93.3 \%$ & $73.7 \%$ \\
\hline $\begin{array}{l}\text { Fund manag. } \\
\text { companies }\end{array}$ & Directly & 57 & 180 & 29 & 58 & $50.9 \%$ & $32.2 \%$ \\
\hline Total & All & 107 & 391 & 71 & 203 & $66.4 \%$ & $51.9 \%$ \\
\hline (Subtotal) & Banks only & 50 & 211 & 42 & 145 & $84.0 \%$ & $68.7 \%$ \\
\hline (Subtotal) & Directly only & 92 & 292 & 57 & 130 & $62.0 \%$ & $44.5 \%$ \\
\hline
\end{tabular}

Note: 7 banks which were directly addressed and received 22 questionnaires are located in Austria 
TABLE 7. Items with significant change over time

\begin{tabular}{|c|c|c|c|c|}
\hline $\begin{array}{l}\text { Questions or } \\
\text { relations }\end{array}$ & $\begin{array}{l}\text { See } \\
\text { Table }\end{array}$ & Response in 1992 & $\begin{array}{l}\text { Response in } \\
2001\end{array}$ & $\begin{array}{l}\text { Impact on } \\
\text { positions }\end{array}$ \\
\hline $\begin{array}{l}\text { Importance of } \\
\text { flow analysis }\end{array}$ & 2 & $17.9 \%$ & $23.5 \%$ & Pos. 1: ? \\
\hline $\begin{array}{l}\text { Flow use and } \\
\text { higher degree of } \\
\text { education }\end{array}$ & 3 & $\begin{array}{l}\text { Negative correla- } \\
\text { tion for all, dealers } \\
\text { and fund managers }\end{array}$ & $\begin{array}{l}\text { Positive correla- } \\
\text { tion for fund } \\
\text { managers }\end{array}$ & $\begin{array}{l}\text { Pos. 1: ? } \\
\text { Pos. 3: ? }\end{array}$ \\
\hline $\begin{array}{l}\text { Flow use and } \\
\text { higher age }\end{array}$ & 3 & - & $\begin{array}{l}\text { Negative corre- } \\
\text { lation for dealers }\end{array}$ & Pos. 1:? \\
\hline $\begin{array}{l}\text { Flow use and } \\
\text { superior position }\end{array}$ & 3 & $\begin{array}{l}\text { Positive correlation } \\
\text { for dealers }\end{array}$ & - & $(\text { Pos. 3: ? })^{(1)}$ \\
\hline $\begin{array}{l}\text { Flow use and } \\
\text { institution size }\end{array}$ & 5 & - & $\begin{array}{l}\text { Positive correla- } \\
\text { tion for fund } \\
\text { managers }\end{array}$ & $\begin{array}{l}\text { Pos. 2: ? } \\
\text { Pos. 3: ? }\end{array}$ \\
\hline $\begin{array}{l}\text { Flow use and } \\
\text { importance of } \\
\text { psychology }\end{array}$ & 8 & $\begin{array}{l}\text { Positive correlation } \\
\text { for all }\end{array}$ & - & Pos. 1: ? \\
\hline $\begin{array}{l}\text { Flow use and } \\
\text { longer time of } \\
\text { information proc- } \\
\text { essing }\end{array}$ & 8 & - & $\begin{array}{l}\text { Positive correla- } \\
\text { tion for fund } \\
\text { managers }\end{array}$ & $\begin{array}{l}\text { Pos. 2: ? } \\
\text { Pos. 3: ? }\end{array}$ \\
\hline
\end{tabular}

Note: "-" indicates no significant relation. ${ }^{(1)}$ The disconnection of flow use and superior position may be influenced by the younger dealers relying stronger on the more modern technique of "flow analysis" (see Section 5). 